\title{
A PERSPECTIVA DO TEXTO NO PROCESSO DA TRADUÇÃO. Sobre a autobiografia Lost in Translation de Eva Hoffman
}

Lost in Translation. A Life in a New Language. Eva Hoffman. New York: Penguin, 1990.

Magdalena Nowinska

Aos doze anos de idade, Eva Hoffman emigrou, junto com os pais e a irmã, da Polônia para os Estados Unidos, com uma passagem pelo Canadá. Sua emigração insere-se na grande onda de emigrações de judeus poloneses após a Segunda Guerra Mundial, causadas por tendências antissemitas na Polônia dos anos 50 e 60 do século XX. Em sua autobiografia, Eva Hoffman apresenta essa emigração como história da perda e da reconstrução de uma identidade, que resulta em "a life in a new language", segundo o subtítulo do livro.

Hoffman subdivide suas memórias em três partes: o "paraíso" ("Paradise") designa um mundo integral, que é perdido e despedaçado quando a família de Hoffman vai para o "exílio" ("Exile"). Apenas em um "mundo novo" ("The New World"), Hoffman consegue recompor o seu mundo e torná-lo de novo relativamente homogêneo. As experiências de Hoffman não são incomuns, a sua experiência de ter perdido um paraíso, a inevitável dor de nostalgia entre exilados, são bastante comuns entre migrantes forçados, embora a sensação de um paraíso recuperado seja talvez menos comum. O ponto interessante do livro, porém, é o seu foco na linguagem como meio de transporte de identidades entre culturas.

Em "Paraíso", Hoffman descreve a infância na Polônia até a chegada do navio no Canadá. Os anos na Polônia do pós-guer-

TradTerm, 17, 2010, p. 195-199 
ra, caracterizados por privações em consequência da Segunda Guerra Mundial e do stalinismo, Hoffman apresenta da perspectiva de uma criança, embora filtrados pela introspecção adulta. O paraíso desta infância consiste, para Hoffman, na unidade de mundo, experiência e linguagem, que é, neste caso, a língua polonesa (Hoffman não aprendeu o iídiche dos pais). Hoffman ilustra o seu conceito da unidade inserindo, no texto inglês, vários conceitos poloneses, explicando com eles a interligação entre significante, referência e conotações pessoais adquiridas por meio da convivência com os dois primeiros.

Em "Exílio", Hoffman descreve os anos no Canadá, os anos de sua adolescência, que terminam com a viagem para os Estados Unidos, uma espécie de segunda emigração. Hoffman vê-se como exilada principalmente no plano psicológico, compreendendo-se como "a psyche that has been forcibly pried from its structures" (p. 104). Para ela, o desarraigamento das estruturas familiares externas - sociais e culturais, tais como família, amigos etc. - é acompanhado pela separação de língua e experiência, "this radical disjoining between word and thing" (p. 107), em consequência da qual ela sente alienação, tanto no que diz respeito ao seu ambiente, como a si mesma. O que acontece, linguisticamente, no exílio, é que experiência e significados se separam, ou seja, palavras de ambas as línguas de Hoffman viram meros indicadores, que não correspondem mais às experiências pessoais: "I don't see what I've seen, don't comprehend what's in front of me" (p. 108). Como exemplo deste processo, Hoffman conta sobre a renomeação de si mesma e de sua irmã na escola canadense: o "Ewa" polonês vira "Eva" inglês, enquanto "Alina", o nome polonês da irmã de Hoffman, vira "Elaine". A professora renomeia as meninas para simplificar a pronúncia de seus nomes, mas para Hoffman o próprio nome vira assim uma mera etiqueta, separada de si mesma: "Our Polish names didn't refer to us; they were as surely us as our eyes or hands. These new appellations, which we ourselves can't yet pronounce, are not us. They are identification tags, disembodied signs pointing to objects that happen to be my sister and myself" ( $p$. 105). A alienação de si mesma, em consequência da separação de linguagem e experiência, é exílio para Hoffman. 
Com a viagem para Houston, Texas, para estudar no Rice College, Hoffman determina para si mesma um novo ponto de partida. A partir deste momento ela está sozinha; seus pais ficam no Canadá, e Hoffman resolve radicar-se nos Estado Unidos. O seu objetivo é tornar-se uma intelectual em Nova York, uma crítica literária; o caminho escolhido é o de uma formação em estudos literários, que Hoffman termina com um doutorado em Harvard. O objetivo de achar um lugar para si, bem como os estudos literários, forçam Hoffman a ocupar-se intensamente com a nova língua, o inglês, escolhido por ela a partir de agora como a nova língua própria para terminar o estado de mudez, em que ela se sente e que para ela é algo "close to the dispossession of one's self" (p. 124). A busca por uma lingua própria vira também uma busca por identidade, no esforço de superar a sensação de alienação. Esse processo é acompanhado por uma gradual renúncia à língua antiga, que sobrevive apenas como um pano de fundo, uma língua de memórias. Apenas com a renúncia ao polonês como fonte de sua própria identidade, Hoffman declara como concluído o passo para um "Mundo Novo", no qual é possivel ter uma vida em uma língua nova.

\section{II}

O título do livro pode confundir um pouco. O livro não trata diretamente daquele tipo de tradução implícita na citação atribuída a Robert Frost, a tradução de textos. Também o conhecido filme de Sofia Coppola, que usa a mesma citação como título, fala de outros aspectos de tradução. O livro de Hoffman fala da autotradução de um indivíduo, a adaptação interna a um ambiente alheio, que, para Hoffman, corresponde à adaptação linguística, à aceitação de uma língua nova. Essa "tradução" vira aqui uma metáfora para o processo individual de transculturação por meio do idioma. Tradução significa, para Hoffman, duas coisas: de um lado, o fato de aprender a falar uma língua; de outro, a aprendizagem de todo o pano de fundo de uma linguagem, das conotações, pessoais e interpessoais, ligadas aos significantes de uma linguagem. Tradução vira assim um processo de penetração de uma cultura por meio de 
linguagem. É no meio deste processo que o indivíduo pode se sentir perdido, "lost in translation".

Isso pode ser compreendido o que se costuma entender como tradução - ou seja, a transposição de textos ou outros sistemas semióticos entre si - no que diz respeito ao desdobramento de significados no texto traduzido. Um texto, traduzido de uma língua para a outra, não se transforma apenas superficialmente, mas por princípio; os significantes novos que substituem os antigos trazem consigo uma bagagem intertextual, conotativa, que muda profundamente o texto traduzido.

\section{III}

Textos não se traduzem a si mesmos. Na verdade, nem Eva Hoffman o faz. A sua "tradução" acontece em um contexto social: a imigrante polonesa-judia vira uma intelectual americana após um processo de socialização em colégios e universidades americanas.

Ao contrário de textos, seres humanos que passam por processos de tradução podem relatar a sua tradução. Um texto, no processo de tradução, transforma-se em um objeto controlado pela mão todo-poderosa do tradutor, que trata o texto, dependendo do seu habitus, com mais ou menos autoridade. O que então Hoffman faz na sua autobiografia é, de certo modo, a apresentação da perspectiva do texto no processo de tradução: as ansiedades, a falta de orientação, a resistência ao novo, o medo de perdas. Hoffman mostra-se, na autobiografia, como um texto dificilmente traduzivel. Como adolescente de doze anos de idade, ela ainda tem uma adaptabilidade suficiente para absorver o novo, mas as suas lembranças e a sua socialização na Polônia são fortes o suficiente para atrapalhar o processo de tradução. Hoffman compara-se com os dois outros exemplos de tradução na sua família, o de seus pais e o de sua irmã. Os pais, que emigram da Polônia como adultos, representam uma tradução estrangeirizadora. Eles levam consigo um pano de fundo cultural muito enraizado e pouca flexibilidade para a adaptação; a sua tradução é apenas superficial. Ao contrário deles, a irmã pequena traduz-se melhor; a sua bagagem cultural é insig- 
nificante, a sua adaptabilidade grande; a sua tradução é uma adaptação fácil.

\section{IV}

É justificada, talvez, a pergunta se e por que um texto quer ser traduzido.

Hoffman manifesta, em vários pontos da sua autobiografia, o desejo de ser "traduzida": "I want to live within language and to be held within the frame of culture" (p. 194), ela escreve. Enquanto exilada de suas linguas, Hoffman descreve-se com expressões de privação; a sua condição é uma "verbally deprived condition" (p. 181). A falta de fala significa invisibilidade "because I'm not heard I feel I'm not seen" (p. 147) -; a invisibilidade significa isolação. Para Hoffman, ser traduzido significa ser inserido dentro de um sistema, dai "the desire for the comfort of being a recognizable somebody placed on a recognizable social map" (p. 140). Ela busca "the comfort that comes from being cradled by continuity, the freedom from insignificance" (p. 160), para escapar da "entropy of inarticulateness" (p. 124).

O desejo de articular-se é certamente mais forte em pessoas que, como Hoffman, trabalham com lingua e textos. Toda a falta de comunicação, porém, provocada pela inabilidade de falar qualquer língua, leva necessariamente a um estado de isolação e de alienação. Da mesma forma que o constata Walter Benjamin para a tradução de textos, o desejo de traduzir-se é o desejo de sobreviver. 